\title{
Observing evidence of insider trading in the Athens Stock Exchange
}

\author{
Eleftherios Thalassinos • Dimitrios Maditinos • \\ Athanasios Paschalidis
}

Received: 22 April 2012 / Accepted: 9 November 2012 / Published online: 3 December 2012 (C) 2012 E. Thalassinos et al.; licensee Springer. This is an Open Access article distributed under the terms of the Creative Commons Attribution License (http://creativecommons.org/licenses/by/2.0), which permits unrestricted use, distribution, and reproduction in any medium, provided the original work is properly cited.

\begin{abstract}
This study proposes a process for observing evidence of insider trading in the Athens Stock Exchange (ASE). This is performed by building an environment which, based upon previous research, common sense and information technology, may be used for observing such evidence. It is designed to be parametrically used for each stock in the sample, perform event study analysis and indicate abnormal performance that might be attributed to insider trading. To some extent, it applies knowledge discovery to retrieve meaningful information from the existing data. In this case, to identify transaction dates that might be associated with certain events. The validity of this process is assessed by relating the identified events to published announcements.
\end{abstract}

JEL Classification $\mathrm{G} 02 \cdot \mathrm{G} 12 \cdot \mathrm{G} 14 \cdot \mathrm{G} 15$

\section{Introduction}

\subsection{Basic concepts}

Information about publicly traded securities which is not publicly available and has a substantial impact on the value of traded securities is referred to as inside informa-

\footnotetext{
E. Thalassinos $(\bowtie)$

Department of Maritime Studies, University of Piraeus, Piraeus, Greece

e-mail: thalassinos@ersj.eu

D. Maditinos

Business Administration Department, Kavala Institute of Technology, Kavala, Greece e-mail: dmadi@teikav.edu.gr
}

A. Paschalidis

Department of Accountancy, Kavala Institute of Technology, Kavala, Greece

e-mail: sakis00@otenet.gr 
tion.' People having access to such privileged information are referred to as 'insiders.' Executives, managers, lawyers, accountants andemployees usually fall into this category of 'primary insiders' (IOSCO 2003, p. 7). Additionally, 'secondary insiders' (IOSCO 2003, p. 9) who acquire access to such privileged information accidentally or involuntarily may also fall into this category (Minenna 2003, p. 65). Transactions performed by insiders taking advantage of privileged inside information are referred to as 'insider trading' (Jaffe 1974).

In Greece, Law 3340/2005, which was established in compliance with the EU Directive 2003/6/EC, provides the legal framework against 'market abuse' caused by exploitation of 'privileged information.' Additionally, Ruling No. 3/347/12.7.2005 of the Hellenic Capital Market Commission dictates disclosure requirements of privileged information, lists of persons having access to privileged information and transaction details disclosure requirements. Such transactions should not be related to privileged information. However, the broad literature reveals that the potential profit from exploiting privileged information is far too great temptation to be measured easily with laws and regulations. During the 1980s, an increased effort was undertaken by the US authorities to restrict insider trading. Seyhun (1992) demonstrated that the enforcement of regulations did not have any impact on insider trading, not even momentarily when a new regulation was imposed (p. 171). Consistently with these results, Seyhun and Bradley (1997, p. 211) find that insider trading takes places even after a company files for bankruptcy when someone would expect that such transactions would be scrutinized. However, there was a decrease in insider trading observed, just before earnings announcements and takeover announcements, presumably because both of these announcements had been at the epicenter of numerous court cases (Seyhun 1992, pp. 171-175).

Legislators, regulators and market participants have set the conceptual boundaries of insider trading. However, when it comes to enforcing laws and regulations, the boundaries are often blurred. For instance, when a member of the board performs a transaction, declares it to the stock market authorities and after some time realizes profits based on privileged information, it is often very hard to prove intentional exploitation of inside information. Insiders often disguise their transactions by trading at apparently unrelated moments or even through proxies. In effect, most studies documenting the various aspects of insider trading are based on officially reported transactions. Moreover, reported transactions are analyzed in regard to some standard sets of information, like earnings announcements, changes in dividends, mergers, acquisitions or even fraud (e.g. Ke et al. 2003; Seyhun and Bradley 1997). There are though important pieces of information that may well have an impact on the value of a firm, like the hiring of a key employee, for instance, or a business agreement, but pass unnoticed. While it is evident that insiders can be all those who perform their transactions based on privileged information, research is mainly based on reported transactions.

\subsection{Aims and objectives}

Insider trading is first of all a company-specific activity that eventually, through its extensive presence, turns into a market-wide phenomenon. So, this study aims at 
proposing a process and an environment suitable for observing severally stock performance that might be attributed to insider trading.

The research approach that has been followed so far, to the extent it was able to be reviewed, is the selection of a specific type of event, like an increased dividends announcement or a merger announcement. Such an approach may be suitable when the effects of insider trading are studied on an aggregate basis. In a firm-specific examination, though, such an approach would probably narrow the scope of research by limiting the examined cases and by completely disregarding unannounced events or firm-specific events. As a result, this study's objective is to construct the proposed environment around a process that can identify informationally significant events which thereafter may be used as the focal points for insider trading activity examination. The ground for the present study is the Athens Stock Exchange (ASE) while it is carried out by utilizing previous research, publicly available sources of information and information technology.

\section{Literature review}

\subsection{Research on insider trading}

Insider trading has been, and still is, at the epicenter of a wide variety of studies. It has also been examined as a 'by-product' or a 'level-gauge' in a great number of works in relation, for instance, to the efficient market hypothesis (e.g. Fama 1970; Fama et al. 1969; Finnerty 1976a; Fama 1991). It has been examined under different contexts, in different financial markets either geographically or functionally. There have been various methodologies applied in various data sets. Insider trading has been examined either by scholars or by legislative and regulating bodies, but on the other hand, it remains at the center of attention of market participants and financial reporters.

Jaffe (1974), in a very concise and detailed manner, provides evidence supporting the argument that insiders do profit from their transactions. He concluded that, in fact, there can be a profitable investment strategy based on this report. Something, of course, that was not compliant with the efficient market hypothesis. Finnerty (1976b) builds upon previous work (by Jaffe 1974; Finnerty 1976a and others) to move one step further. He demonstrates that insiders not only outperform the market, but there is, in fact, a causal relationship between insiders' trading and future accounting and financial information. To put it another way, insiders do trade based upon their privileged information.

Since it had already been demonstrated that insiders earned abnormal returns, Givoly and Palmon (1985) examined whether, and to what degree, those abnormal returns were due to the close monitoring of insider trading by outsiders or to the disclosure of specific information. Although their research did confirm that insiders earned abnormal returns, they found no evidence to support a direct link with specific events.

Despite abundant research work, a causal relationship between insider trading and abnormal returns can, generally, only be implied. That is mainly due to the fact that 
there is an inherent difficulty in precisely identifying time as an attribute of this relationship. Damodaran and Liu (1993), however, managed to time the moment when private information was acquired. They established thus a direct link between the distinct stages of the insider trading process, providing evidence that insiders do exploit their privileged information and earn abnormal returns.

The vast majority of research papers examining insider trading are based on data from US stock markets. Consequently, Del Brio et al. (2002) provide valuable insight in their research on insider trading based on data from the Spanish stock markets, the Madrid Stock Exchange (MSE) and the Spanish Continuous Market (CM). The applicability of previous results can, thus, be tested in a less vigorous, less studied and potentially, somehow, less efficient environment than the stock markets in US. They, too, build upon previous research (Jaffe 1974; Finnerty 1976a and others) to conclude that insiders do profit from their transactions, consequently rejecting the hypothesis of the strong form efficiency as defined by the EMH. They also suggest that the regulatory framework fails to inhibit insider trading. In their study, they examined daily transaction data and reported transactions by insiders.

The London Stock Exchange (LSE) is the ground for an insightful study by Hillier and Marshall (2002). They conduct their study upon the fact that, under the London Stock Exchange Model Code, there is a ban in transactions by insiders two months before the announcement of earnings both interim and final. Although, as shown by previous research, insiders do comply with the ban, they manage to outperform the market. This fact questions the efficacy of the specified ban and reveals the need for more sophisticated regulation or none at all.

\subsection{Research approaches}

Typically, research into insider trading is performed by conducting an event study. The methodology applied is based on the research by Fama et al. (1969). They examined the way stock prices are adjusted to reflect newly arrived information. Their aim was to test market efficiency by studying the impact split announcements have on stock prices through their implied increase in dividends.

In the years that followed the publication of Fama, Fisher, Jensen and Roll's research, event study methodology was applied in many research works on various subjects. Kothari and Warner (2004) reported that up to that moment, more than 500 event studies had been published.

Effectively, in an event study, a model is applied to estimate the difference between the normally Expected Return (ER) and the Return (R) of a stock within a timeframe of a specific event. The estimated residuals or Abnormal Returns (AR) are cumulated to form the Cumulated Abnormal Returns (CAR). Finally, CAR is tested statistically to examine whether the null hypothesis holds $\left(\mathrm{H}_{0}: \mathrm{CAR}=0\right)$ or the alternative hypothesis that CAR is statistically different from zero holds $\left(\mathrm{H}_{1}: \mathrm{CAR} \neq 0\right)$.

Specifically, first of all, the event that will be examined has to be defined. For different scopes of research, various events are selected. Subsequently, the event may be an earnings announcement, a merger or acquisition announcement, a change in regulations affecting a specific business sector or even a natural disaster. Secondly, a timeframe around the specified event has to be selected. Over this 'event window,' 
(MacKinlay 1997, p. 14) the selected security prices are examined to determine the effect of the event. The event window consists of a pre-event period, the event day and the post-event period. The pre-event period, may vary from 15 months to a few days, 20 days being a reasonable selection in insider trading studies examining daily data. The event day is the announcement day or the day on which the event is made known to the public by any means. The post-event period is typically one or just a few days after the event day.

Next, available data are selected, examined, filtered and prepared in order to become suitable for the scope and requirements of certain research (MacKinlay 1997, p. 15). Research has been conducted using monthly (e.g. Jaffe 1974), daily and even intraday data. The use of daily data, however, seems to prevail (Kothari and Warner (2004), p. 8) and certainly provides more accuracy than monthly data (MacKinlay 1997, p. 35), especially for studying insider trading. Monthly data examination may not reveal insider trading activity that might take place a few days before the announcement day (Keown and Pikerton 1981, p. 856). Intraday data, on the other hand, although much more accurate, add complexity because they have to be combined with bid-ask spreads at the specific moment of insider trading transaction to determine the effect on security prices.

The next task is to select the model, according to which Abnormal Return is estimated. At this stage, the researcher has to assume which model attributes 'normal' performance more accurately. MacKinlay (1997, pp. 17-19) cites the several models that have been used in different event studies and which are very briefly mentioned here. Under the Constant Mean Return Model, the abnormal return is estimated as the residual of the observed security price and the mean return of the security. On the other hand, using the Market Model, the Expected Return is derived from the relation of a certain security with the market portfolio. Abnormal Return, thus, is assessed as the residual of the observed security price and the Expected Return. Capital Asset Pricing Model (e.g. Finnerty 1976a; Penman 1982), Arbitrage Pricing theory and various multifactor models have also been applied to estimate the Expected Return. However, as Fama (1991, pp. 1603 and 1604) proposes, '... [one can use] market model or historical average returns, to abstract from normal expected returns without putting unnecessary constraints on the cross-section of expected returns.' As a result, the Market Model is selected for the purposes of current research to assess the Expected Return of the selected securities. So, Abnormal Returns $\left(\mathrm{AR}_{i t}\right)$ of a $(i)$ security in time $(t)$ are estimated as: $\mathrm{AR}_{i t}=\mathrm{R}_{i t}-\alpha_{i}-\beta_{i} \mathrm{R}_{\mathrm{m} t}$ (MacKinlay 1997, $\mathrm{p}$. 20). $\mathrm{R}_{i t}$ is the observed Return of security $(i)$ in time $(t)$ and $\mathrm{R}_{\mathrm{m} t}$ is the observed Market Return in time $(t) . \alpha_{i}$ and $\beta_{i}$ are the Market Model parameters for security (i) estimated by performing linear regression with the Ordinary Least Squares $(\mathrm{O} \backslash \mathrm{S})$ method.

\subsection{Methodological issues}

The selection of firm-specific events is influenced by the ability to gather adequate event data and relevant precise announcement dates. Additionally, as it is presumably evident from the literature review, insider trading is interchangeably used to describe both reported transactions and illegal insider trading. In the first case, insider trading 
is supposed to be irrelevant to the studied event. Otherwise, insiders should be prosecuted. The performance of insiders is examined as if it was relevant to the event. By disregarding this anomaly, one can either question the relevance of the results or accept the insinuation that insiders perform disguised transactions through proxies along with the transactions they report.

On the other hand, illegal insider trading has been examined following three approaches. The first one was to examine prosecuted insider trading in regard to a specific security. The second approach was to derive the presence of insider trading by '[s]ystematic abnormal movements' (Keown and Pikerton 1981, p. 855) before the public announcement. Finally, the third approach was to examine the impact based on a set of prosecuted insider trading cases. In fact, that is what Lisa Meulbroek (1992) did when she studied a set of 183 'insider trading episodes' spanning a 15-year period from 1974 to 1989.

Another issue that needs to be considered is that the events that may be examined present distinct characteristics. Consequently, results and their interpretation may differ for different types of events. For instance, in an increased earnings announcement, there may be just a few people who might exploit their access to privileged information. On the contrary, in a merger announcement, there may be hundreds of people involved (Keown and Pikerton 1981, p. 857) for a longer period of time. As a result, insider trading activity may be less traceable and extended over a wider time period.

\subsection{Research design}

A recapitulation of literature review indicates that, first of all, numerous studies have demonstrated that insider trading is a market-wide phenomenon occurring around any, though none could claim every, event that has a significant informational value. Event study methodology seems to be the most frequently used and appropriate method to study insider trading. The Market Model is adequate in evaluating the abnormal performance due to a specific event and subsequently insider trading around this event (see Fama 1991; MacKinlay 1997; Meulbroek 1992).

Events having a positive effect on stock performance are expected to have different characteristics than those having a negative effect. Moreover, some events have a greater impact than others (Meulbroek 1992). As a result, it was decided to narrow the scope of the Event Detection process, which will be later analyzed, focusing on events having a positive impact on stock performance beyond a predefined benchmark.

Research is conceptually divided into four processes: Dataset Construction, Insider Trading Observation process, Insider Trading Observation Evaluation and Event Detection Evaluation.

Dataset Construction, including data selection, retrieval, cleansing and manipulation, is presented first. Market Model parameters are then estimated using the Athens Stock Exchange General Index (GI) as a proxy for normal performance. At the end of this process a data view is prepared to be used further on.

Next, Insider Trading Observation process is presented. One of the main features of this process, and probably one of the significant outcomes of the present study, is the Event Detection process which is analytically presented and documented including the rationale behind it. Next, the Announcements and News Retrieval procedure 
is presented. This procedure assists the observer in assessing the significance of the Detected Event Dates. The Event Study process which is performed for the selected event date according to a desired set of parameters is then presented. Event Study results are reflected automatically in a graph. The parameters of the Event Detection process, the Detected Event Dates, announcements and news retrieved, the Event Study parameters and results graphically depicted are then integrated into the Insider Trading Observation Window.

Insider Trading Observation Evaluation is presented next. First, the dataset used as the ground of evaluation is described and analyzed. The execution of this procedure generates results for a pre-specified set of Event Detection parameters which are next examined to evaluate the Insider Trading Observation process.

The Event Detection Validity Assessment, which aims to explore whether the Event Detection process actually produces dates which have a high informational value and can thus be characterized as Event Dates, is then presented. In order to perform such an examination, a new dataset is constructed using previous results along with additional data retrieved from the Athens Stock Exchange website (www.ase.gr). Hypothesis development is then described, performed and tested. Empirical results are next presented and evaluated. The workflow of each of the four outlined processes is depicted in Fig. 1.

\subsection{Dataset construction}

Data were obtained through the Athens Stock Exchange website (http://www.ase.gr). They were checked for inconsistencies such as missing or erroneous transaction dates. They were also randomly checked with prices reported on company websites. No errors were found. The main body of data consists of daily transactions spanning time period from $1 / 1 / 2006$ to $31 / 8 / 2008$. They include stock code, transaction date, closing price, change $(\%)$, Volume, Highest price, Lowest price, Total Value of Transactions, Opening Price and the International Securities Identification Number (ISIN). Transaction data before 31/12/2005 were no longer available on the Athens Stock Exchange website and so they were not included. Data after 31/8/2008 were intentionally left out because fluctuations, caused by the economic crisis which broke out in September 2008, might render transaction data unsuitable for the purposes of the present study. Furthermore, auxiliary data including distributed dividends and General Index quotes were also downloaded from the ASE website.

Next, stocks lacking transaction data during the specified time period, either because they were listed after 1/1/2006 or unlisted before 31/8/2008 were excluded along with stocks with insufficient liquidity or long suspension intervals. Stocks no longer listed in October 2009 were also excluded to avoid continuity concerns reflected on stock prices. Daily changes were adapted for dividends while necessary updates and adjustments were also performed.

Linear regression was performed using the OLS method for estimating alpha $(\alpha)$ and beta $(\beta)$ coefficients for each stock in relation to the General Index (GI). The model is based on the classical market model and is of the following form: $\mathrm{R}_{i t}=$ $\alpha_{i}+\beta_{i t} \mathrm{R}_{\mathrm{m} t}+\varepsilon_{i t}$, where $\mathrm{R}_{i t}$ is the return on stock $i$ at a period $t, \mathrm{R}_{\mathrm{m} t}$ is the return on market (here General Index) at a period $t, \varepsilon_{i t}$ is the zero mean disturbance term, and $\alpha$ and $\beta$ are the coefficients for each stock. 


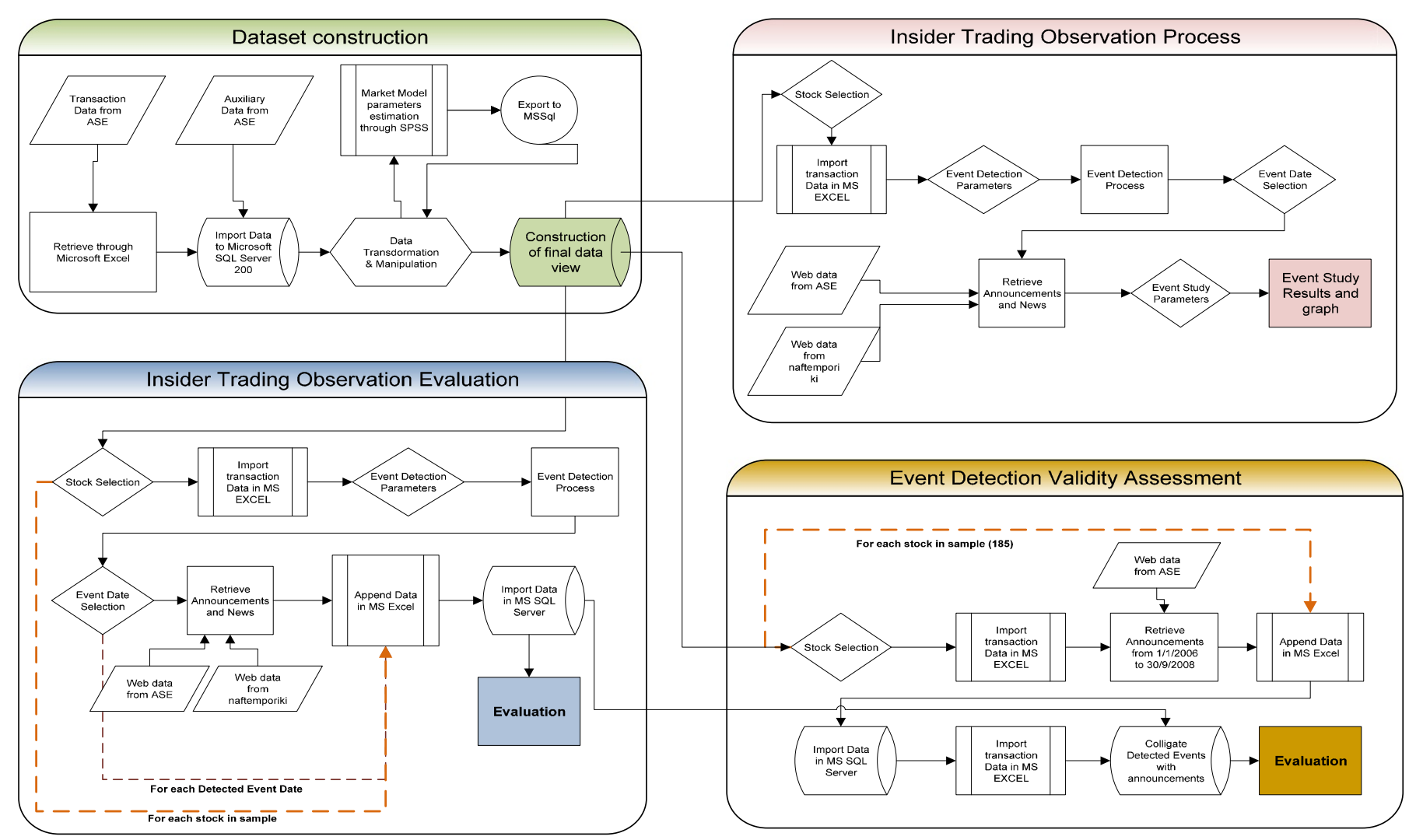

Fig. 1 Workflow of the four processes developed throughout the present research 
Transaction data, Market Model coefficients $(\alpha)$ and $(\beta)$, estimated through linear regression and General Index (GI) data were then combined to form the final dataset of the Data Selection process. Additionally, linear regression coefficients were used to estimate Normal Returns (NR) and Abnormal Returns (AR) based on GI change. Finally, a dataset was formulated by combining transaction data, Market Model parameters and calculating Normal Returns and Abnormal Returns. This dataset consists of 122,517 records of transaction data of 185 stocks.

\section{Insider Trading Observation process}

\subsection{Description}

This section refers to the assembly of an environment which may be used for observing insider trading. It is presented in the sequence it was constructed, which may not necessarily coincide with the way it might be used. The Event Detection process is first analyzed. Next, the Event Study process is documented. The Insider Trading Observation Window, which refers to the integration of the previously analyzed processes, is then presented. Finally, News and Announcements Retrieval features are integrated to enhance the Insider Trading Observation process.

\subsection{Event Detection process}

The rationale behind the Event Detection process is a combination of results from previous research and some common sense, into a set of parametrically defined criteria (Fig. 2). It will be incrementally presented along with some technical details of its implementation. Throughout the rest of the document, the terms 'Event Date,' 'Detected Event Date' and 'transaction date with high informational value' will be used interchangeably. For the purposes of current research, they represent the occurrence of events having a significant positive impact on stock performance.

First of all, in order to isolate possible events that have a significant positive impact on stock performance, a Real Return benchmark was applied (Fig. 2). This benchmark may and should vary among different stocks since the performance of each stock may present different characteristics. For the purposes of Insider Trading process evaluation and Event Detection process validity assessment, evaluation, which will be described later, was set to $3 \%$ in attempt to include events with rather highly positive information content.

The Abnormal Return benchmark (Fig. 2), which in fact is the primary benchmark, was applied to locate abnormal stock performance that could be associated with an event. It may also vary among different stocks but was also set to $3 \%$, for the purposes of evaluation, to include events with rather highly positive informational content.

At this point, it was obvious that there was a concentration of Abnormal Returns that satisfied the above set criteria around a potential event date, maybe because of insider trading activity. In order to distinguish which one of the neighboring transaction dates might in fact be an event date, stock price could be used as a proxy. Yet instead of using stock prices, which would have to be adjusted for dividends and 


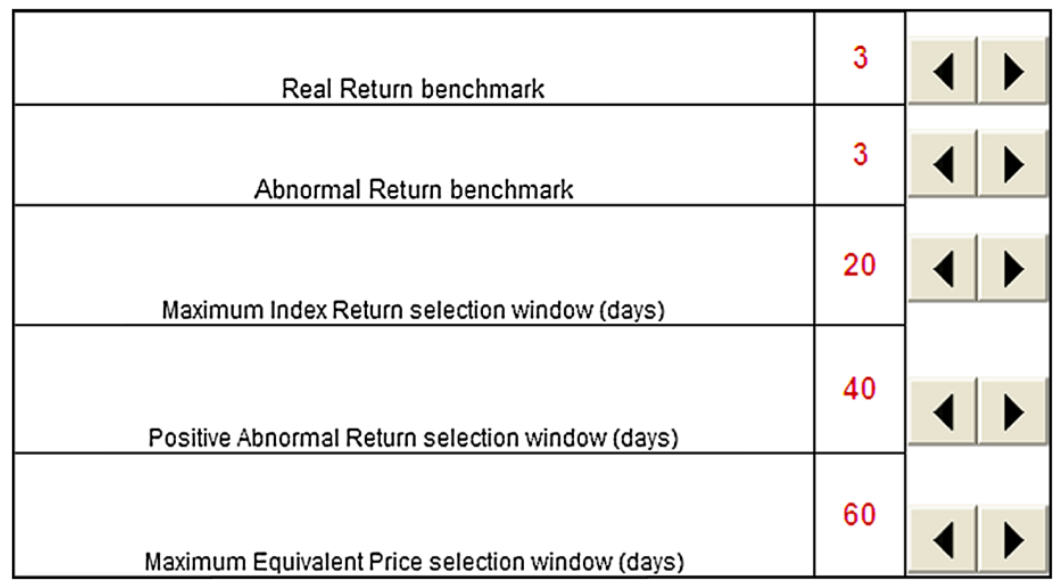

Fig. 2 Parametrically set criteria applied through the Event Detection process

splits, an Equivalent Stock Price was calculated having one as base price on the first transaction date and calculated on each date using the already adjusted daily change.

On an Event Date, stock performance should exceed previous performance. Thus, using the Equivalent Stock Price as a proxy of stock performance, it could be stated that the Equivalent Stock Price on an Event Date should be higher than previous ones. To determine 'previous,' a Maximum Equivalent Price selection window (days) criterion was created (Fig. 2). It was arbitrarily set to 60 days for the purposes of evaluation. According to the Efficient Market Hypothesis (Fama 1970) and under the assumption that the Greek Stock Market is efficient (Dasilas 2007), information is immediately reflected on stock prices. So, the Abnormal Return on an event date should be higher than any other observed abnormal return on neighboring transaction dates. To define how many transaction dates would be taken into consideration a Positive Abnormal Return selection window (days) was implemented (Fig. 2). It was set to 40 days, meaning that the abnormal return on an Event Date should be higher than any other abnormal return for a period of 20 transaction days before and 20 transaction days after the Detected Event Date. A selection of a different time period is always possible, but selecting a much wider time period would question the relevance of observations to the Detected Event Date.

Next, to dissociate the observed abnormal return on a selected date with a general market run-up, a Maximum Index Return selection window (days) criterion was created (Fig. 2). The observed abnormal return should not coincide with the highest value of the General Market Index (GI) return (IR) within a timeframe. This timeframe was arbitrarily set to 20 transaction days around the examined transaction date.

Results satisfying the above criteria indicate that according to the presented rationale and for the specified criteria values, substantial information must have been impounded on the selected company's stock price. Therefore, for the purposes of current research, the relevant transaction dates are regarded as Event Dates. 


\begin{tabular}{|c|c|c|}
\hline Pre-Event Window (days) & 30 & $>$ \\
\hline Post-Event Window (days) & 5 & 4 \\
\hline Market Model Estimation window(days) & 30 & 4 \\
\hline Cumulated Abnormal Return benchmark & 1,5 & 4 \\
\hline \multirow{3}{*}{ 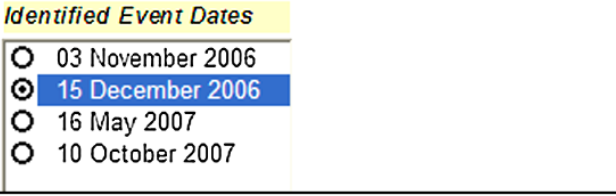 } & \multirow{2}{*}{\multicolumn{2}{|c|}{$\begin{array}{c}\text { Cumulated } \\
\text { Abnormal Retrun } \\
\text { before event date }\end{array}$}} \\
\hline & & \\
\hline & & $49 \%$ \\
\hline
\end{tabular}

Fig. 3 Parametrically set criteria applied through the Event Study process

\subsection{Event study}

For an event study to be performed, certain characteristics have to be defined. First of all, the selection of the event to be studied has to be identified. With the previously described process, it is assumed that the Event Date is the identified date matching the described criteria.

Next, the event window has to be defined. For the purposes of the currently presented individual Insider Trading Observation process, a parametric approach was adopted. For the sake of demonstration, the Pre-Event Window (Fig. 3) was set to 30 transaction days, equivalent to approximately 40 calendar days. Lisa Meulbroek (1992, p. 1672) reports that 'insider trading takes place 13.2 trading days... before the inside information is publicly announced.' The Post-Event Window (Fig. 3) is commonly set to one day. However, for observation purposes, a time span of five transaction days, which is equivalent to approximately one week, was selected.

Market Model Estimation Window (Fig. 3) is the time span used to estimate the Market Model coefficients prior to the Pre-Event Window to avoid any interaction with the Event Window. Typically, a 75 period or more is used. Selecting such a window, though, would exclude event dates detected within four months from the beginning of the observation period which is $1 / 1 / 2006$. So, it was set to 30 transaction days. Besides that, setting different values for this parameter did not seem to alter results as far as Abnormal Return is concerned.

In a typical event study, the observed Abnormal Returns are related to transactions performed by insiders based either on reports they submit to stock exchange authorities or, in the case of prosecuted cases, based on identified transactions (Meulbroek 1992). These Abnormal Returns then are accumulated to form Cumulated Abnormal Returns (CAR). However, in the context of the present observation process, this is not possible. As a result, it is assumed that all significant Abnormal Returns within the Pre-Event Window might imply insider trading activity. In order to define significance a Cumulated Abnormal Return benchmark (Fig. 3) is used. Lisa Meulbroek 


\begin{tabular}{|c|c|c|c|c|c|c|c|c|c|}
\hline & A & $B$ & $\mathrm{C}$ & $\bar{D}$ & $E$ & $F$ & $\mathrm{G}$ & $\mathrm{H}$ & I \\
\hline 1 & $\begin{array}{l}\text { Selected } \\
\text { Event Date }\end{array}$ & $16 / 5 / 2007$ & $\begin{array}{l}\text { Event } \\
\text { Data } \\
\text { Row }\end{array}$ & 342 & $\begin{array}{c}\text { Market } \\
\text { Model } \\
\text { parameters }\end{array}$ & a value & 0,1956 & b value & 1,0209 \\
\hline 2 & $\begin{array}{c}\text { Row } \\
\text { number }\end{array}$ & $\begin{array}{c}\text { Transaction } \\
\text { Date }\end{array}$ & $\begin{array}{c}\text { Real } \\
\text { Return }\end{array}$ & $\begin{array}{c}\text { Index } \\
\text { Return }\end{array}$ & $\begin{array}{l}\text { Normal } \\
\text { Return }\end{array}$ & $\begin{array}{c}\text { Abnormal } \\
\text { Return }\end{array}$ & $\begin{array}{c}\text { Cumulated } \\
\text { Abnormal } \\
\text { Return }\end{array}$ & & \\
\hline 3 & 315 & $4 / 4 / 2007$ & $-1,38$ & 0,99 & 1,21 & $-2,59$ & 0,00 & & \\
\hline 4 & 316 & $5 / 4 / 2007$ & 0,52 & $-0,05$ & 0,14 & 0,38 & 0,00 & & \\
\hline 5 & 317 & $10 / 4 / 2007$ & 0,70 & 0,91 & 1,12 & $-0,42$ & 0,00 & & \\
\hline 6 & 318 & $11 / 4 / 2007$ & 0,86 & 1,00 & 1,22 & $-0,36$ & 0,00 & & \\
\hline 7 & 319 & $12 / 4 / 2007$ & $-0,86$ & $-0,47$ & $-0,28$ & $-0,58$ & 0,00 & & \\
\hline 8 & 320 & $13 / 4 / 2007$ & 0,17 & 1,00 & 1,22 & $-1,05$ & 0,00 & & \\
\hline 9 & 321 & $16 / 4 / 2007$ & 2,24 & 1,20 & 1,42 & 0,82 & 0,00 & & \\
\hline 10 & 322 & $17 / 4 / 2007$ & 0,34 & $-0,32$ & $-0,13$ & 0,47 & 0,00 & & \\
\hline 11 & 323 & $18 / 4 / 2007$ & $-2,02$ & $-0,93$ & $-0,75$ & $-1,27$ & 0,00 & & \\
\hline 12 & 324 & $19 / 4 / 2007$ & $-0,34$ & $-0,59$ & $-0,41$ & 0,07 & 0,00 & & \\
\hline 13 & 325 & $20 / 4 / 2007$ & 2,07 & 1,41 & 1,64 & 0,43 & 0,00 & & \\
\hline 14 & 326 & $23 / 4 / 2007$ & $-2,36$ & $-0,55$ & $-0,37$ & $-1,99$ & 0,00 & & \\
\hline 15 & 327 & $24 / 4 / 2007$ & $-0,52$ & $-0,56$ & $-0,38$ & $-0,14$ & 0,00 & & \\
\hline 16 & 328 & $25 / 4 / 2007$ & 2,60 & 0,95 & 1,17 & 1,43 & 0,00 & & \\
\hline 17 & 329 & $26 / 4 / 2007$ & $-0,17$ & 0,37 & 0,57 & $-0,74$ & 0,00 & & \\
\hline 18 & 330 & $27 / 4 / 2007$ & $-1,19$ & $-1,28$ & $-1,11$ & $-0,08$ & 0,00 & & \\
\hline 19 & 331 & $30 / 4 / 2007$ & $-0,17$ & $-1,16$ & $-0,99$ & 0,82 & 0,00 & & \\
\hline 20 & 332 & $2 / 5 / 2007$ & $-0,86$ & 0,82 & 1,03 & $-1,89$ & 0,00 & & \\
\hline 21 & 333 & $3 / 5 / 2007$ & 0,35 & $-0,14$ & 0,05 & 0,30 & 0,00 & & \\
\hline 22 & 334 & $4 / 5 / 2007$ & 2,76 & 0,55 & 0,76 & 2,00 & 2,00 & & \\
\hline 23 & 335 & $7 / 5 / 2007$ & $-1,68$ & 0,51 & 0,72 & $-2,40$ & 2,00 & & \\
\hline 24 & 336 & $8 / 5 / 2007$ & $-0,85$ & $-1,63$ & $-1,47$ & 0,62 & 2,00 & & \\
\hline 25 & 337 & $9 / 5 / 2007$ & $-0,52$ & 0,05 & 0,25 & $-0,77$ & 2,00 & & \\
\hline 26 & 338 & $10 / 5 / 2007$ & 2,25 & 0,49 & 0,70 & 1,55 & 3,56 & & \\
\hline 27 & 339 & $11 / 5 / 2007$ & 0,34 & $-0,54$ & $-0,36$ & 0,70 & 3,56 & & \\
\hline 28 & 340 & $14 / 5 / 2007$ & 3,38 & 1,13 & 1,35 & 2,03 & 5,59 & & \\
\hline 29 & 341 & $15 / 5 / 2007$ & 1,80 & 1,16 & 1,38 & 0,42 & 5,59 & & \\
\hline 30 & 342 & $16 / 5 / 2007$ & 5,94 & 0,37 & 0,57 & 5,37 & 10,95 & & \\
\hline 31 & 343 & $17 / 5 / 2007$ & 1,52 & $-0,07$ & 0,12 & 1,40 & 10,95 & & \\
\hline 32 & 344 & $18 / 5 / 2007$ & $-0,15$ & 0,46 & 0,67 & $-0,82$ & 10,95 & & \\
\hline 33 & 345 & $21 / 5 / 2007$ & $-2,84$ & 0,38 & 0,58 & $-3,42$ & 10,95 & & \\
\hline 34 & 346 & $22 / 5 / 2007$ & $-1,23$ & $-0,27$ & $-0,08$ & $-1,15$ & 10,95 & & \\
\hline 35 & 347 & $23 / 5 / 2007$ & 1.56 & 0.66 & 0.87 & 0.69 & 10.95 & & \\
\hline
\end{tabular}

Fig. 4 Event Study results worksheet (example)

(1992, p. 1677) reports an average of $3.06 \%$ of Abnormal Returns on Insider Trading days but with values ranging from $0.07 \%$ in restructuring announcement cases to $8.15 \%$ in hostile tender offer cases. In the presented example, it was set to $1.5 \%$. Consequently, Cumulated Abnormal Returns are the aggregated Abnormal Returns over the selected Cumulated Abnormal Return benchmark.

The linear regression to estimate the Market Model coefficients is performed dynamically and, eventually, an Event Study is also performed dynamically according to the selected variables.

An example of the results of an Event Study is displayed in Fig. 4.

\subsection{Observing insider trading}

The Event Detection process and the Event Study process, presented earlier, serve as the ground for the Insider Trading Observation Window and the procedures associated with it (Fig. 5). The Observation Window offers the ability to examine each 


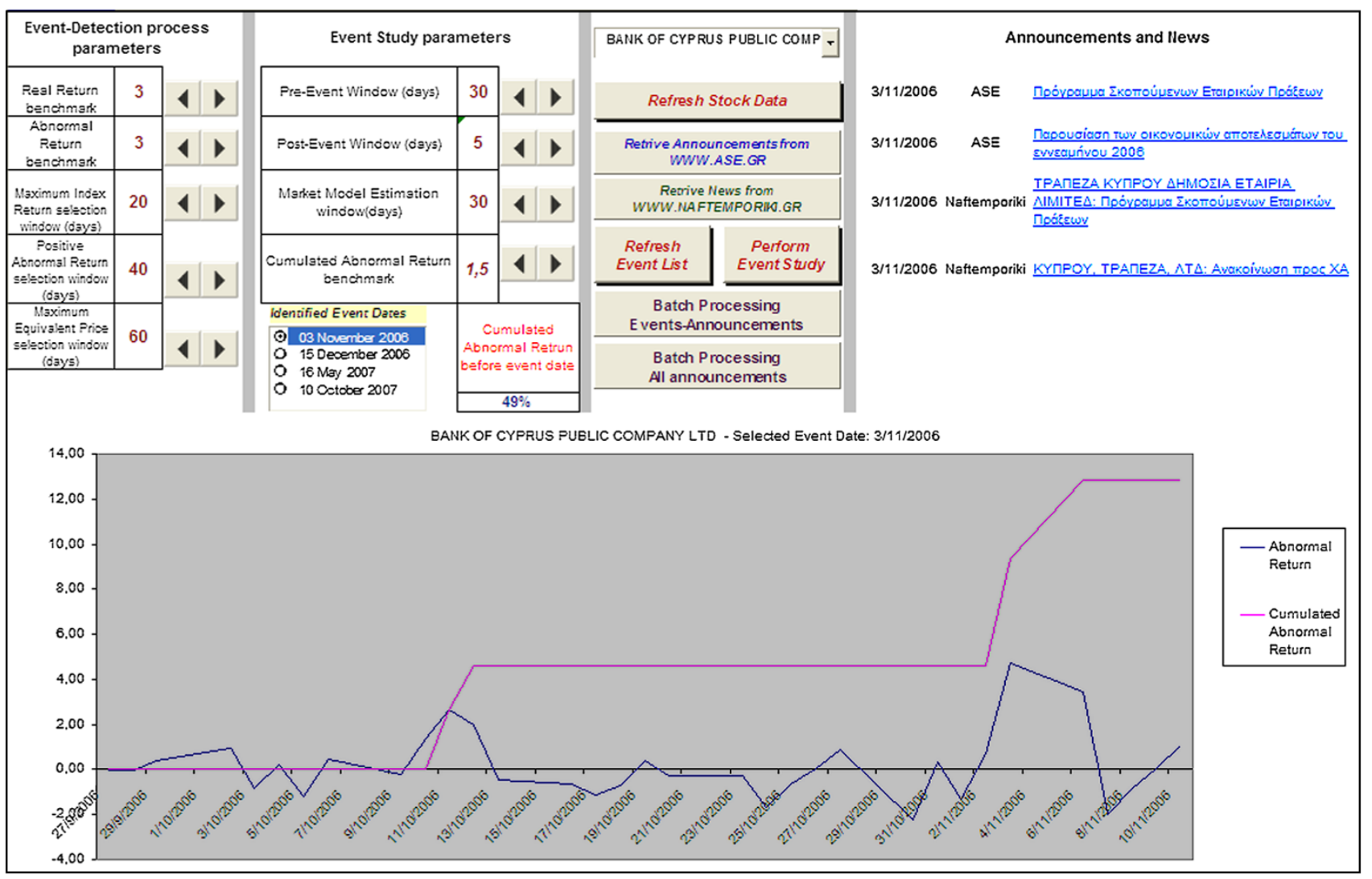


one of the selected stocks for each one of the detected event dates. A user is able to select various Event Detection parameters and perform an Event Study according to a desired set of parameters. An announcements and news retrieval feature, which will be next presented, assists in evaluating the significance of an identified event.

The whole process is designed to operate dynamically, regardless of the selected stock. First of all, the stock to be examined is selected by using the relevant list box (Fig. 5). By pressing the Refresh Stock Data button (Fig. 5), data for the selected stock are imported and Event Detection, as described earlier, is performed. Finally, an Event Study is performed. Results are automatically reflected in the relevant graph (Fig. 5).

At this point, it has to be mentioned that the whole Insider Trading Observation process is based on the detection of transaction dates on which there seems to be a significant informational impounding on stock prices. Consequently, the validity of the results is only speculative, unless there can be a juxtaposition of the detected events with actual events. To perform such juxtaposition, one has to search for news about the selected stock around the detected event date, comprehend their importance and evaluate their relevance to the detected event.

To facilitate this search and, thus, improve the functionality of the whole process, an Announcements and News Retrieval Procedure was implemented to retrieve announcements around the detected event dates from the Athens Stock Exchange website (http://www.ase.gr/content/en/announcements/companiespress/) and news from the financial newspaper Naftemporiki (www.naftemporiki.gr).

\subsection{Review of presented features}

Through the presented Insider Trading Observation Window (Fig. 5), a user is able to detect transaction dates which might be of significant informational value according to a desired set of parametrically set criteria. Then, an Event Study may be performed according to the parametrically set criteria for each of the detected event dates. Results of the performed Event Study are presented and are graphically depicted on a graph on the Insider Trading Observation Window (Fig. 5). Finally, a user may perform further research by retrieving announcements and news around the selected date. By selecting any of the retrieved announcements or news hyperlink, further details are presented on an Internet browser.

\section{Insider Trading Observation process evaluation}

\subsection{Insider Trading Observation process results}

The event detection process may, and possibly should, be performed using a different set of parameters according to the specific characteristics of each stock. However, for the sake of evaluation of this process, event detection was performed for all stocks included in the selected sample for a fixed set of parameters. It was assumed, thus, that to characterize a transaction date as an Event Date, there should be observed on that day: (a) a Real Return of more than $3 \%$, (b) an Abnormal Return of more than 
$3 \%$, (c) the Abnormal Return should be higher than any of those observed 20 days before and 20 days after the specific date. Moreover, (d) the price of the stock should be, on that day, higher than any other observed during the last 60 transaction dates; and finally, (e) the Index Return should not coincide with the highest value of the last 20 transaction dates.

By pressing the 'Batch Processing All announcements' button (Fig. 5), data for each stock in the sample are retrieved, Event Detection is performed along with Announcement and News Retrieval for each Detected Event Date. Results are then appended in a dataset for all stocks in the sample to be further examined.

\subsection{Evaluation of Insider Trading Observation process results}

Performing a primary examination of some simple statistics, it may be inferred that, in general, the event detection process produced satisfactory results in 180 out of 185 stocks included in the sample detecting 640 Event Dates, with an average of 3.46 events per stock. It may also be noted that in $77 \%$ of detected event dates, there was at least one announcement or news publication retrieved which might be relevant to Insider Trading. There were 765 Announcement or News Dates, out of which 483 were retrieved from ASE and 282 from Naftemporiki (www.naftemporiki.gr). The search in the Athens Stock Exchange website (www.ase.gr) was performed in an accurate manner based on the id of each stock. On the contrary, the search for news in the Naftemporiki website was performed based on the company name. Consequently, there is an absolute degree of certainty for the 483 Announcement Dates from ASE. In relevance to Fig. 5 and considering the less accurate procedure of News Retrieval from Naftemporiki, the 282 News Dates is a rather satisfactory result.

At this point, it has to be reminded that the Announcement and News Retrieval procedure performs an examination spanning up to four days before and fourteen days after the detected event date. To further examine the distribution of announcement or news across the selected time span, weekends were taken into consideration to increase the accuracy of observations. As a result, the time span is actually reduced to four working days before and twelve working days after the detected event date.

Results indicate a high concentration of Announcements or News on and around the detected event dates. Out of the 765 Announcement and News Dates, $69 \%$ are concentrated within two working days of the detected event dates. Two explanations may be provided to interpret this, somehow unexpected, result. It is either the product of coincidence or the Event Detection process documented earlier generates, in fact, results which correspond to dates with significant informational value. However, it has to be mentioned that the Announcements and News Retrieval period spans from four days before to fourteen days after the detected event date. Thus, results for time periods greater than two days may be one directionally biased. Consequently, the validity of Event Detection process had to be further assessed.

\subsection{Evaluation of Insider Trading Observation process}

The Insider Observation process, as it was already pointed out, refers to the selection of an environment which may be used for observing evidence of Insider Trading. It 
provides Event Detection capabilities while it may be used for conducting an Event Study around detected Event Dates and even retrieves Announcements and News to evaluate the significance of an Event. So far, it has been demonstrated, that for a fixed set of parameters, satisfactory results are produced.

The evaluation of a process, even though aimed at providing tools to assist subjective observation of insider trading, can only be subjectively evaluated. What was demonstrated so far was the relevance of the proposed processes to Insider Trading Observation. An accurate evaluation would require transaction details, information about specific transactions and even special inquiries, possible only for the Athens Stock Exchange authorities. Subsequently, as an evaluation of the proposed process, only a personal testimony of the writer may be presented.

Observing Insider Trading through the proposed process refers to three distinct elements. The first one is the examination of whether the Detected Event Date can be associated with a specific Announcement or News publication. In about $30 \%$ of the examined cases, the Announcements and News Retrieval Procedure did locate information which, through naked eye, could be possibly associated with some significant event. Further evaluation of this significance would require extensive examination, something which would be beyond the aims of current research.

The second element observed was the presence of Abnormal Returns before an Event Date, depicted in the Event Study graph. In all cases examined, there were Abnormal Returns observed beyond the specified Cumulated Abnormal Returns benchmark (Fig. 5) at least once throughout the examined Event Window. In most examined cases, the benchmark was set to $1.5 \%$. So, through this process and in the specified context, Insider Trading activity is indeed observed in all Events detected.

Finally, the Cumulated Abnormal Return ratio before Event Date, displayed in Fig. 5, was observed to be between $30 \%$ and $80 \%$. This ratio refers to the Cumulated Abnormal Returns until one day before the Event Date as a percentage of Cumulated Abnormal Returns until the Event Date. It actually represents the amount of Insider Trading activity performed before the Event Date and certainly within the selected Event Window. Setting the Cumulated Abnormal Returns benchmark to values other than $1.5 \%$, did not seem to have a drastic effect on Cumulated Abnormal Returns ratio.

As a result, it would be stated that, according to the above observed elements, the Insider Trading Observation process assists in Observing Evidence of Insider Trading in the Athens Stock Exchange. However, a reproduction and possibly improvement of this process would certainly be appreciated.

\section{Event Detection process validity assessment}

\subsection{Research rationale}

The Event Detection process described earlier aims at discovering transaction dates of high informational value irrelevant to the existence of officially published announcements. These transaction dates may then be used as reference dates for conducting Event Studies to check for insider trading activity. However, to assess the validity of such a process, published information may be used as a proxy. 
The rationale behind the Event Detection Validity Assessment is that if the detected event dates in fact represent dates with high informational value, there should be more information published on or around the detected event dates than on other transaction dates.

\subsection{Dataset construction and description}

All announcements published in the Athens Stock Exchange website for the selected sample of 185 stocks and for the examined time period spanning from 1/1/2006 to $31 / 8 / 2008$ were retrieved. Announcements for September 2008 were also included to be later used during the Event Detection Evaluation process. This procedure is executed by pressing the 'Batch Processing All announcements' button included in the Stock Performance Observation Window (Fig. 5) presented earlier. Results from the above procedure include stock symbol, announcement date, announcement title in Greek and URL of the announcement.

There were 20,708 announcements retrieved for the 185 stocks included in the sample on 695 distinct dates. 149 announcements were published on ten distinct dates with no transactions performed. Finally, there were no transaction dates with no published announcements. Oddly enough, announcements seem to be increasing from Monday through Friday.

The dataset which will be used to assess the validity of the Event Detection process derives from the colligation of two datasets. The first one was created earlier through the Insider Trading Observation process evaluation and consists of Detected Event Dates. The second dataset consists of all announcements published on a time period spanning 20 working days before to 20 working days after the Detected Event Dates, selected from the Total Announcements dataset of 20,708 announcements. Consequently, a time frame of 41 working days, equivalent to approximately two months, will be used to examine the distribution of announcements around each Event Date to include observations distant enough from the Detected Event Dates. The selection of a 41-day timeframe was also selected considering the Central Limit Theorem requirement of a sufficiently large sample $(n \geq 30)$. On the other hand, performing tests with a wider time frame did not seem to provide any additional insight. There are 640 detected event dates for 180 out of 185 stocks included in the sample. The Event Detection process failed to detect events for five stocks. As a result, these stocks and the relevant announcements were not included in the data set. Furthermore, announcements for the selected timeframe for each detected event date were aggregated for each one of the 180 stocks. There were only ten announcements on Saturdays and Sundays while there are 20,109 announcements related to the 180 stocks in the dataset. Moreover, none of these announcements were published within the selected timeframe of 41 working days. As a result, disregarding weekends has no effect on the dataset. Partial results are analytically displayed in Table 1.

\subsection{Logical verification of Events-Announcements dataset}

A question that may arise when results in Table 1 are observed is how many announcements would normally be expected within the selected timeframe. There is an 
Table 1 Event-Announcements dataset, representing the number of Announcements within a timeframe of 41 working days around the Detected Event Dates for each stock

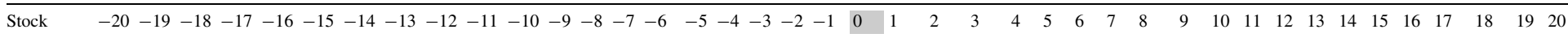
$\begin{array}{lllllllllllllllllllllllllllllllllllllllllllllllllllllll}\text { AEGEK } & 0 & 1 & 0 & 1 & 0 & 3 & 1 & 1 & 2 & 1 & 0 & 4 & 0 & 1 & 2 & 2 & 3 & 0 & 2 & 0 & 2 & 0 & 1 & 2 & 2 & 2 & 1 & 0 & 1 & 1 & 0 & 2 & 0 & 5 & 0 & 1 & 3 & 0 & 1 & 0 & 1\end{array}$

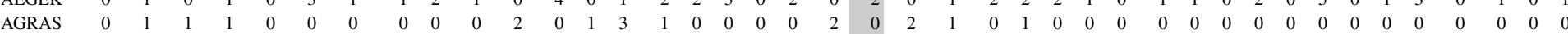
AKRIT

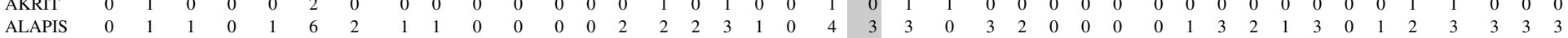
ALCO $\quad 0 \quad 000000001$ ALKA $\quad 0 \quad 001100000$

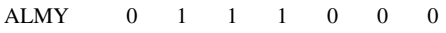

$\begin{array}{llllllll}\text { ALTEC } & 1 & 0 & 0 & 0 & 0 & 0 & 0 \\ \text { ALTER } & 0 & 0 & 0 & 0 & 0 & 0 & 0\end{array}$

$\begin{array}{llllllll}\text { ANDRO } & 2 & 2 & 0 & 0 & 0 & 1 & 0\end{array}$

$\begin{array}{llllllll}\text { ANEK } & 0 & 0 & 0 & 0 & 1 & 0 & 0 \\ \text { ARBA } & 1 & 2 & 1 & 1 & 4 & 0 & 2\end{array}$

$\begin{array}{llllllll}\text { ARBA } & 1 & 2 & 1 & 1 & 4 & 0 & 2 \\ \text { ASCO } & 0 & 0 & 0 & 0 & 0 & 0 & 0\end{array}$

$\begin{array}{lrrrrrrr}\cdots & \cdots & \cdots & \cdots & \cdots & \cdots & \cdots & \cdots \\ \text { SPRDER } & 5 & 0 & 4 & 2 & 4 & 0 & 3\end{array}$

$\begin{array}{llllllll}\text { TATT } & 0 & 1 & 2 & 1 & 0 & 0 & 1\end{array}$

$\begin{array}{llllllll}\text { TEGO } & 0 & 0 & 0 & 0 & 0 & 0 & 1 \\ \text { TELET } & 0 & 0 & 1 & 0 & 0 & 0 & 0\end{array}$

$\begin{array}{llllllll}\text { TELET } & 0 & 0 & 1 & 0 & 0 & 0 & 0 \\ \text { TELL } & 1 & 1 & 3 & 4 & 1 & 0 & 2\end{array}$

$\begin{array}{llllllll}\text { TEMP } & 1 & 2 & 4 & 0 & 0 & 0 & 0 \\ \text { TGEN } & 0 & 0 & 0 & 0 & 0 & 0 & 0\end{array}$

$\begin{array}{llllllll}\text { TGEN } & 0 & 0 & 0 & 0 & 0 & 0 & 0 \\ \text { TITK } & 1 & 0 & 1 & 0 & 0 & 0 & 0\end{array}$

$\begin{array}{llllllll}\text { TPEIR } & 0 & 2 & 3 & 1 & 3 & 2 & 0\end{array}$

$\begin{array}{llllllll}\text { TRASTOR } & 0 & 0 & 0 & 0 & 0 & 0 & 0\end{array}$

$\begin{array}{llllllll}\text { UTEX } & 0 & 0 & 0 & 0 & 0 & 0 & 0 \\ \text { VARDA } & 0 & 0 & 0 & 0 & 0 & 0 & 0\end{array}$

$\begin{array}{llllllll}\text { VARNH } & 0 & 0 & 0 & 0 & 0 & 0 & 1 \\ \text { VELL } & 1 & 0 & 0 & 1 & 1 & 0 & 1\end{array}$

$\begin{array}{llllllll}\text { VELL } & 1 & 0 & 0 & 1 & 1 & 0 & 1 \\ \text { VIVER } & 0 & 0 & 0 & 0 & 0 & 1 & 0\end{array}$

$\begin{array}{llllllll}\text { VOVOS } & 0 & 0 & 0 & 0 & 0 & 0 & 0\end{array}$

$\begin{array}{llllllll}\text { XAKO } & 0 & 2 & 0 & 0 & 0 & 0 & 0\end{array}$

$\begin{array}{llllllll}\text { XALY } & 0 & 0 & 0 & 0 & 0 & 0 & 1 \\ \text { YALCO } & 0 & 0 & 0 & 0 & 0 & 0 & 0\end{array}$

$\begin{array}{lllllllllllll}0 & 0 & 1 & 0 & 2 & 0 & 0 & 0 & 0 & 0 & 0 & 0 & 0\end{array}$

$\begin{array}{llllllllllllll}1 & 0 & 0 & 0 & 0 & 1 & 0 & 2 & 2 & 0 & 0 & 0\end{array}$

$\begin{array}{llllllllllllllllll}0 & 1 & 0 & 1 & 0 & 1 & 2 & 1 & 0 & 1 & 1 & 0 & 6 & 0\end{array}$

$\begin{array}{lllllllllllllllllll}0 & 0 & 0 & 0 & 0 & 0 & 1 & 1 & 0 & 0 & 0 & 1 & 0 & 0\end{array}$

$\begin{array}{lll}0 & 1 & 0\end{array}$

$\begin{array}{lllllllllll}1 & 1 & 0 & 3 & 0 & 2 & 0 & 2 & 1 & 0 & 1\end{array}$

$\begin{array}{llllllllllll}0 & 0 & 0 & 2 & 1 & 0 & 1 & 0 & 0 & 1 & 1\end{array}$

$\begin{array}{rrrrrrrrrrrrr} & \cdots & \cdots & \cdots & \cdots & \cdots & \cdots & \cdots & \cdots & \cdots & \cdots & \cdots & \cdots \\ 4 & 2 & 5 & 2 & 3 & 2 & 2 & 2 & 1 & 5 & 3 & 2 & \\ 0 & 0 & 1 & 0 & 0 & 0 & 0 & 0 & 0 & 0 & 0 & 0 & \end{array}$

$\begin{array}{lllllllllllll}0 & 0 & 1 & 0 & 0 & 0 & 0 & 0 & 0 & 0 & 0 & 0 & 0\end{array}$

$\begin{array}{llllllllllllllll}0 & 1 & 0 & 0 & 0 & 0 & 1 & 1 & 1 & 0 & 0 & 1\end{array}$

$\begin{array}{lll}0 & 0 & 1\end{array}$

$\begin{array}{llllllllllll}2 & 0 & 0 & 1 & 0 & 0 & 2 & 3 & 1 & 0 & 2 & 0\end{array}$

$\begin{array}{llllllllllllll}2 & 1 & 2 & 0 & 3 & 0 & 0 & 0 & 2 & 1 & 1 & 1 & 0\end{array}$

$\begin{array}{llllllllllll}0 & 0 & 0 & 0 & 0 & 0 & 0 & 0 & 0 & 0 & 0 & 0 \\ 0 & 0 & 0 & 0 & 0 & 0 & 0 & 0 & 1 & 1 & 0 & 1\end{array}$

$\begin{array}{llllllllllll}2 & 1 & 3 & 1 & 1 & 1 & 0 & 1 & 1 & 2 & 1 & 1 \\ 0 & 1 & 0 & 0 & 0 & 0 & 0 & 0 & 0 & 0 & 0 & 0\end{array}$

$\begin{array}{llllll}1 & 2 & 0 & 0 & 0 & 2\end{array}$

$\begin{array}{lllllllllllllllll}1 & 0 & 1 & 1 & 0 & 1 & 0 & 1 & 0 & 0 & 0 & 0\end{array}$

$\begin{array}{llllllllllll}0 & 1 & 0 & 0 & 0 & 0 & 0 & 1 & 0 & 0 & 2 & 0\end{array}$

$\begin{array}{llllllllllll}0 & 2 & 0 & 1 & 1 & 0 & 0 & 0 & 0 & 1 & 0 & 1\end{array}$

$\begin{array}{llllllllllll}0 & 0 & 0 & 1 & 0 & 0 & 0 & 0 & 0 & 0 & 0 & 0\end{array}$

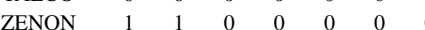

$\begin{array}{llllllllllll}0 & 1 & 1 & 2 & 0 & 0 & 0 & 0 & 1 & 0 & 0 & 0 \\ 0 & 0 & 0 & 0 & 0 & 1 & 0 & 0 & 0 & 0 & 0 & 0\end{array}$

$\begin{array}{llllllllllll}0 & 0 & 0 & 0 & 0 & 0 & 1 & 1 & 0 & 0 & 0 & 1\end{array}$

$\begin{array}{lllllll}1 & 0 & 0 & 0 & 0 & 0 & 0\end{array}$

$\begin{array}{lllllllllllll}0 & 0 & 0 & 0 & 0 & 0 & 0 & 0 & 0 & 0 & 0 & 0 & 0\end{array}$

$\begin{array}{lllllllllllllllllllll}1 & 0 & 1 & 1 & 1 & 1 & 1 & 1 & 1 & 2 & 2 & 0 & 0 & 1 & 1 & 2 & 0 & 0 & 0 & 0 & 1\end{array}$

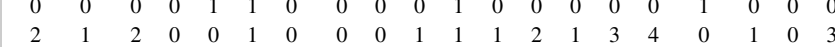
$\begin{array}{llllllllllllllllllll}0 & 0 & 0 & 0 & 1 & 0 & 1 & 0 & 1 & 0 & 1 & 0 & 1 & 1 & 0 & 0 & 1 & 0 & 0 & 0\end{array}$ $\begin{array}{lllllllllllllllllllll}1 & 1 & 1 & 3 & 0 & 0 & 0 & 1 & 0 & 0 & 0 & 1 & 1 & 0 & 1 & 0 & 0 & 0 & 0 & 0 & 1\end{array}$ $\begin{array}{lllllllllllllllll}0 & 0 & 0 & 0 & 0 & 0 & 0 & 0 & 1 & 0 & 0 & 0 & 0 & 0 & 0\end{array}$ $\begin{array}{lllllllllllllllllllll}1 & 0 & 0 & 0 & 1 & 1 & 1 & 2 & 3 & 0 & 0 & 0 & 0 & 0 & 1 & 0 & 1 & 1 & 3 & 1 & 0\end{array}$ $\begin{array}{lllllllllllllllllllll}2 & 1 & 2 & 2 & 1 & 0 & 0 & 1 & 1 & 2 & 1 & 0 & 1 & 1 & 1 & 0 & 2 & 1 & 0 & 0 & 1 \\ 0 & 0 & 0 & 0 & 0 & 0 & 0 & 0 & 0 & 0 & 0 & 0 & 1 & 0 & 0 & 0 & 0 & 1 & 1 & 0 & 0\end{array}$ $\begin{array}{lllllllllllllllllllll}2 & 0 & 1 & 0 & 0 & 3 & 0 & 0 & 1 & 0 & 0 & 0 & 0 & 0 & 1 & 1 & 2 & 1 & 0 & 0 & 0\end{array}$ $\begin{array}{lllllllllllllllllllllllllllll}0 & 0 & 0 & 0 & 0 & 0 & 0 & 0 & 0 & 0 & 0 & 0 & 0 & 0 & 1 & 1 & 0 & 0 & 0 & 0 & 0\end{array}$ $\begin{array}{llllllllllllllllllllllllll}0 & 1 & 3 & 0 & 1 & 0 & 0 & 0 & 0 & 0 & 0 & 0 & 0 & 0 & 0 & 0 & 0 & 0 & 0 & 0 & 0 & 0 & 0 & 0 & 0 & 0\end{array}$ $\begin{array}{llllllllllllllllllllllllllllllllllllllllllllllllll}\text { Total } & 88 & 76 & 87 & 73 & 78 & 82 & 77 & 100 & 70 & 87 & 88 & 75 & 77 & 93 & 104 & 81 & 86 & 90 & 98 & 115 & 145 & 130 & 108 & 101 & 94 & 83 & 89 & 78 & 104 & 98 & 91 & 93 & 85 & 94 & 94 & 92 & 93 & 108 & 114 & 91 & 93\end{array}$ 
Table 2 Partial view of Expected daily Announcements per Stock

\begin{tabular}{lllll}
\hline Stock & Date & $\begin{array}{l}\text { Average } \\
\text { Announcements per } \\
\text { Stock }\left(\mu_{\mathrm{DA} \sigma}\right)\end{array}$ & $\begin{array}{l}\text { Standardized daily } \\
\text { Announcements } \\
\left(\mathrm{W}_{\mathrm{DA} t}=\mathrm{DA}_{t} / \mu_{\mathrm{DA}}\right)\end{array}$ & $\begin{array}{l}\text { Expected } \\
\text { Announcements } \\
\left(\mathrm{E}_{\mathrm{A} \sigma t}\right)\end{array}$ \\
\hline AEGEK & $24 / 5 / 2007$ & 0.23453 & 1.10345 & 0.25879 \\
AEGEK & $25 / 6 / 2007$ & 0.23453 & 0.79310 & 0.18601 \\
AEGEK & $26 / 6 / 2008$ & 0.23453 & 2.13793 & 0.50141 \\
AGRAS & $18 / 12 / 2006$ & 0.06619 & 0.82759 & 0.05478 \\
AGRAS & $16 / 5 / 2007$ & 0.06619 & 0.82759 & 0.05478 \\
AGRAS & $23 / 4 / 2008$ & 0.06619 & 1.58621 & 0.10499 \\
AGRAS & $6 / 6 / 2008$ & 0.06619 & 2.44828 & 0.16204 \\
AKRIT & $24 / 8 / 2006$ & 0.05755 & 0.68966 & 0.03969 \\
AKRIT & $22 / 9 / 2006$ & 0.05755 & 0.58621 & 0.03374 \\
AKRIT & $27 / 12 / 2006$ & 0.05755 & 0.62069 & 0.03572 \\
\hline
\end{tabular}

average of 29 announcements per day with a very high standard deviation of 15.74. There is also a high variability in the number of Announcements across time. As it would be expected, there is a high concentration of announcements around dates when annual or periodic results are submitted. Aggregating announcements occurring each month for years 2006 and 2007 reveal that in June, for instance, there are twice as many announcements than in January. There are more announcements in June and November by approximately $40 \%$ or more than in any other month. Furthermore, statistics for Announcements per day results indicates no normality in the number of announcements across time. Skewness and Kurtosis are both greater than one, the mode is quite different than the mean, while there are also multiple modes observed.

Aggregating announcements for each stock leads to an average of 111 announcements for each stock but with a very high standard deviation of 77.44. Announcements for each stock vary from as high as 511 to as low as 14. Examination of Announcements per stock results indicates there is no normality in the number of announcements per stock. Skewness and Kurtosis are both greater than one while the mode is quite different than the mean. It is evident, thus, that announcement occurrence depends both upon time and stock.

To approximate the expected number of announcements for the selected time frame of 41 days, both the stocks, included in the sample, and the dates, either detected event dates or dates around them, have to be taken into consideration.

First of all, the daily average number of announcements $\left(\mu_{\mathrm{DA} \sigma}\right)$ for each stock $(\sigma)$ was calculated for the examination period from 1/1/2006 to 31/8/2008 plus September 2008. Then, the daily average number of announcements was calculated $\left(\mu_{\mathrm{DA}}\right)$, which is, as noted earlier, 29 . This average $\left(\mu_{\mathrm{DA}}\right)$ is used as the denominator to standardize daily announcements for each date $(t) \mathrm{DA}_{t} / \mu_{\mathrm{DA}}$. This fraction $\left(\mathrm{W}_{\mathrm{DA} t}\right)$ represents the informational weight of each transaction date. Finally, expected announcements $\mathrm{E}_{\mathrm{A} \sigma t}$ for each stock $(\sigma)$ for each transaction date $(t)$ are derived by multiplying $\mu_{\mathrm{DA} \sigma}$ with $\mathrm{W}_{\mathrm{DA} t}$. A part of the results is displayed in Table 2.

Next, results for each working date were combined and aggregated to produce the full set of expected announcements for each observation date within the timeframe 
of 41 working days. Totals from Observed Announcements in Table 1 and Expected Announcements are displayed together in Table 3. They are also graphically depicted in Fig. 6. By simply looking at the results in Table 3 and Fig. 6, it may be noticed that Observed Announcements, generally, move around Expected Announcements, indicating, first of all, that the Expected Announcements calculation is rather accurate. On dates $(-1),(0)$ and $(+1)$, however, Observed Announcements clearly outnumber Expected Announcements. In fact, differences at these three observation points are the highest within the entire observation window. On Day (-1) Observed Announcements are $25 \%$ higher than Expected Announcements, on Day (0) $56 \%$ and on Day (+1) $44 \%$.

\subsection{Hypothesis}

Evaluation of the Event Detection process validity, in the context of the present study, may be performed by examining published information in the form of Announcements in the ASE website (www.ase.gr) on and around the Detected Event dates. Therefore, out of results displayed in Table 3, the total number of Announcements on and around Day (0), which represents the total number of Announcements on Detected Event Dates, may be examined in juxtaposition to the total number of Announcements for the rest of the dates within the observation window of 41 working days.

According to the Efficient Market Hypothesis, since the Greek Stock Market is considered efficient (Dasilas 2007), all available information is instantly impounded on stock prices. Day $(-1)$ thus was included in the sample representing the effect of some event because some announcements may be published after or just before the closing of stock market. In such a case, impounding of information on stock prices should happen on the next market day. On the other hand, Day $(+1)$ was included because sometimes the market may learn the news from newspapers or other sources while an official announcement might be published on the next day. In fact, announcements on Day $(+1)$, as it can be observed in Table 3 are considerably higher than announcements on Day $(-1)$, implying perhaps that in many cases information is impounded on stock prices before their public announcement.

Consequently, what will be examined here, is whether the average Observed Announcements on Days $(-1),(0)$ and $(+1)$ is different from the average of Observed Announcements for the rest of Days within the observation window of 41 working days.

To perform this test, two samples were formed out of results in Table 3. Sample A consists of Observed Announcements on Days from (-20) to $(-2)$ and $(+2)$ to $(+20)$, while Sample B consists of observations for Days $(-1),(0)$ and $(+1)$.

The null hypothesis will be that the mean of total Observed Announcements on Days $(-1),(0)$ and $(+1)\left(\mu_{\mathrm{B}}\right)$, referred to as Sample B, is not statistically significantly different from the mean of announcements on days ranging from $(-20)$ to $(-2)$ and from $(+2)$ to $(+20)\left(\mu_{\mathrm{A}}\right)$, referred to as Sample A. Thus, the null hypothesis is as follows:

$$
\mathrm{H}_{0}: \mu_{\mathrm{B}}=\mu_{\mathrm{A}}
$$


Table 3 Totals of Observed Announcements in Table 1 and Expected Announcements

\begin{tabular}{|l|c|c|c|c|c|c|c|c|c|c|c|c|c|c|c|c|c|c|c|c|c|c|c|c|c|c|c|c|c|c|c|c|c|c|c|c|c|c|c|c|c|c|c|c|c|}
$\begin{array}{l}\text { Working Days } \\
\text { Distance }\end{array}$ & -20 & -19 & -18 & -17 & -16 & -15 & -14 & -13 & -12 & -11 & -10 & -9 & -8 & -7 & -6 & -5 & -4 & -3 & -2 & -1 & 0 & 1 & 2 & 3 & 4 & 5 & 6 & 7 & 8 & 9 & 10 & 11 & 12 & 13 & 14 & 15 & 16 & 17 & 18 & 19 & 20 \\
\hline
\end{tabular}

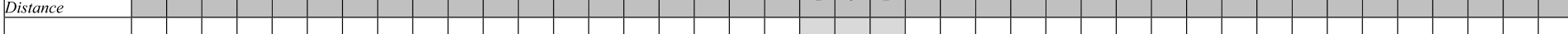

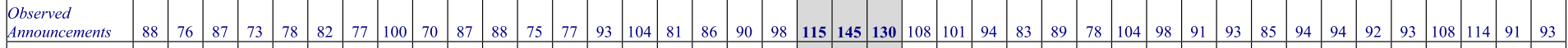
\begin{tabular}{|l|l|l|l|l|l|l|l|l|l|l|l|l|l|l|l|l|l|l|l|l|l|l|l|l|l|l|l|l|l|l|l|l|l|l|l|l|l|l|l|l|l|l|l|l|l|l|l|l|l|}
\hline $\begin{array}{l}\text { Expected } \\
\text { Announcements }\end{array}$ & 79 & 82 & 82 & 81 & 83 & 85 & 86 & 86 & 87 & 85 & 86 & 84 & 82 & 84 & 85 & 87 & 87 & 92 & 92 & 92 & 93 & 90 & 89 & 88 & 91 & 93 & 92 & 91 & 92 & 93 & 93 & 90 & 90 & 92 & 91 & 93 & 91 & 95 & 97 & 97 & 99 \\
\hline
\end{tabular}

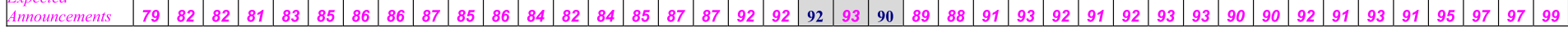
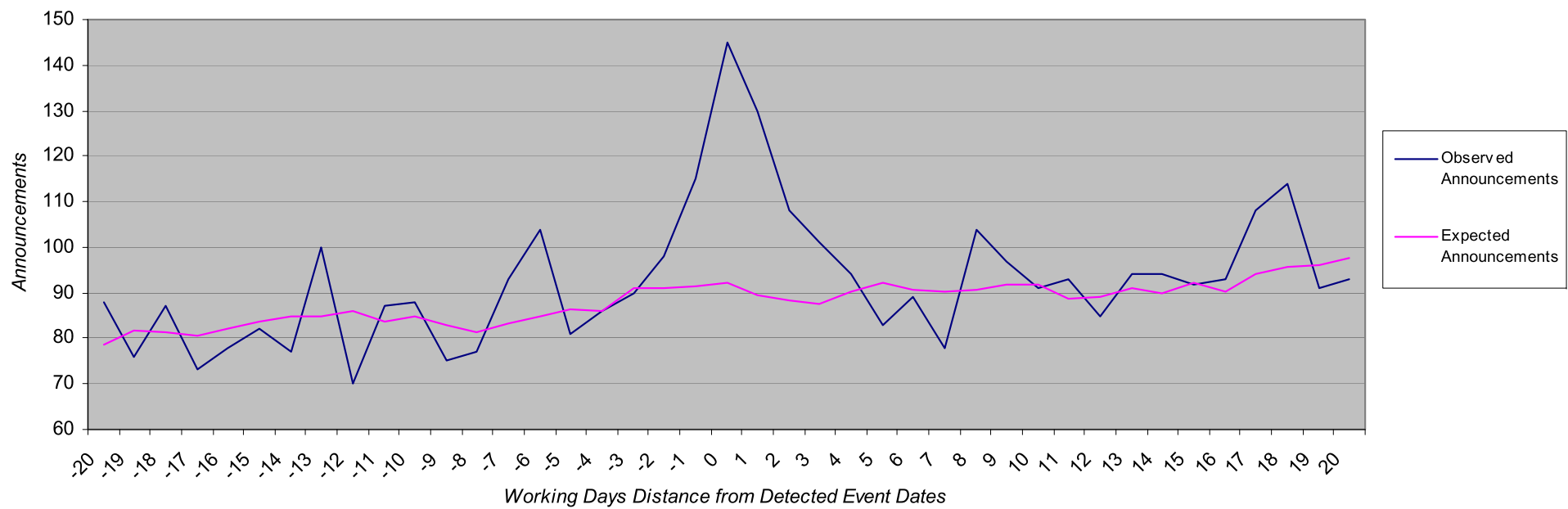

Fig. 6 Graph representing Observed Announcements and Expected Announcements within the timeframe of 41 days 
The alternative hypothesis is that the mean of announcements of Sample B $\left(\mu_{\mathrm{B}}\right)$ is greater than the mean of announcements of Sample A. Thus, the Alternative Hypothesis is as follows:

$$
\mathrm{H}_{\mathrm{A}}: \mu_{\mathrm{B}}>\mu_{\mathrm{A}}
$$

\subsection{Independence of observations and normality}

Out of the 663 transaction dates included in the original sample of transactions, from 1/1/2006 to 31/8/2008, there are Detected Event Dates on 279 different dates. Moreover, Observation Dates created within the -20 to +20 timeframe range from $16 / 2 / 2006$ to $22 / 9 / 2008$. There are 678 working days within this period and there are also 678 announcement Observation Dates.

Additionally, placing Detected Event Dates, monthly aggregated for years 2006 and 2007, next to monthly announcements for years 2006 and 2007, we may observe that the Announcement seasonality mentioned earlier does not apply to the Detected Event Dates produced through the Event Detection process. As a result, we may regard that Observation Dates included within the $(-20)$ to $(+20)$ timeframe represent the population of transactions and announcements relieved from seasonality bias. The only bias that exists is the fact that observations are aligned around Detected Event Dates which are supposed to represent observations with high informational value. Removing the $(-1)$ to $(+1)$ observations, though, permits us stating that the $(-20)$ to $(-2)$ and $(+2)$ to $(+20)$, Sample A, represents the population of transactions and announcements relieved from Detected Event Dates bias.

Furthermore, in order to examine whether Sample A represents satisfactorily the population of transactions and announcements and assuming that the Expected Announcements in Table 3 represent the population, a one sample $t$-test is performed. It is tested whether the mean of Sample A $\mu_{\mathrm{A}}$ is statistically significantly different from the mean of Expected Announcements ( $\left.\mu_{\mathrm{eA}}\right)$ (Table 3), stating thus an auxiliary null hypothesis $\mathrm{HaO}$ along with an alternative Ha1.

$$
\mathrm{Ha} 0: \mu_{\mathrm{A}}=\mu_{\mathrm{eA}}
$$

and

$$
\mathrm{Ha} 1: \mu_{\mathrm{A}} \neq \mu_{\mathrm{eA}} \text {. }
$$

First, testing for normality of Expected Announcements, we observe that the Mean (88.9722) is very close to the Median (90.0799) while Skewness and Kurtosis are within the -1 to +1 range. Additionally, both the Kolmogorov-Smirnov and the Shapiro-Wilk significances are greater than the level of significance of 0.05. So, we may state that Expected Announcements are normally distributed.

Testing for normality of Sample A, we observe that the Mean (89.8158) is very close to the Median (90.5), while Skewness and Kurtosis are within the -1 to +1 range. Both the Kolmogorov-Smirnov and the Shapiro-Wilk significances are greater than the level of significance of 0.05. So, we may assume that Sample A is normally distributed.

Performing a one sample $t$-test on Sample A against the Expected Announcements mean $\mu_{\mathrm{eA}}=88.97$, we get a two-tailed significance of 0.621 which is considerably 
Table 4 One-sample test of Sample A against the mean of Sample B

\begin{tabular}{lllllll}
\hline & \multicolumn{2}{l}{ Test value $=130$} & & \\
\cline { 2 - 7 } & $t$ & $\mathrm{df}$ & Sig. (2-tailed) & $\begin{array}{l}\text { Mean } \\
\text { difference }\end{array}$ & $\begin{array}{l}\text { 95 \% confidence interval } \\
\text { of the difference }\end{array}$ \\
\cline { 5 - 7 } & & & & Lower & Upper \\
\hline Sample A & -23.672 & 37 & 0.000 & -40.18421 & -43.6238 & -36.7446 \\
\hline
\end{tabular}

higher than the significance level (alpha) of 0.05. So, we fail to reject the null hypothesis that the mean of Sample A $\mu_{\mathrm{A}}$ is statistically significantly different from the mean of Expected Announcements $\mu_{\mathrm{eA}}$. Moreover, the fact that the two-tailed significance is so high and the $\mu_{\mathrm{eA}}$ of 88.97 is so close to $\mu_{\mathrm{A}} 89.82$ might imply that Sample A in fact represents accurately the population of announcements and transactions.

\subsection{Testing the hypothesis and interpretation of results}

To test the null hypothesis $\mathrm{H}_{0}: \mu_{\mathrm{B}}=\mu_{\mathrm{A}}$, a one sample $t$-test is performed in Sample A with the mean of Sample B $\left(\mu_{\mathrm{B}}=130\right)$ as a test value.

Statistics displayed in Table 4 indicate that with a $t$ statistics of -23.672 the twotailed probability is less than 0.000 . So, the null hypothesis $\mathrm{H}_{0}: \mu_{\mathrm{B}}=\mu_{\mathrm{A}}$ is rejected. Furthermore, for $t=-23.672$, the one-tailed probability is also less than 0.000 . Since the mean of Sample B is greater than the mean of Sample A and complies with the sign (-) of $t$ statistics, we accept the alternative hypothesis $\mathrm{H}_{\mathrm{A}}: \mu_{\mathrm{B}}>\mu_{\mathrm{A}}$.

By accepting the alternative hypothesis $\mathrm{H}_{\mathrm{A}}: \mu_{\mathrm{B}}>\mu_{\mathrm{A}}$, it can be assumed that there are more announcements on Days $(-1),(0)$ and $(+1)$ than on other days around these days. Moreover, since observations in Sample A match the results from Expected Announcements, it may be stated that there are more announcements on Days $(-1),(0)$ and $(+1)$ than it would be expected under normal conditions, that is, if there were no Events matching the criteria set through the Event Detection process. Results on Day (0) represent announcements on Detected Event Dates. So, it may also be stated, that, in fact, transaction dates included in Day $(-1),(0)$ and $(+1)$ observations have a higher informational value than the rest of observations. It is reasonable to conclude thus that the Event Detection process which produced dates used for forming observations on Day (0) was in fact successful.

\section{Conclusions}

\subsection{Concluding remarks}

The aim of this study was to develop an environment which, based upon existing research mainly on event study methodology, could be used for observing insider trading in the Athens Stock Exchange by exploiting publicly available information and utilizing information technology. It was demonstrated that the Insider Observation 
process, materialized mainly in the Insider Observation Window, offers the ability to observe the evidence of Insider Trading.

Instead of building this environment around dates of specific significance, a process was developed to detect dates with high informational value for the stock under examination. This process, referred to as Event Detection process was constructed based to a degree upon previous research and to a degree upon common sense. It was designed to be parametrically used according to the specific characteristics of each stock and the subjective judgment of a researcher. Nevertheless, for purposes of evaluation, a test conducted with a fixed set of parameters showed that the Event Detection process does succeed in locating transaction dates with highly positive informational value. Consequently, through this process, it may be feasible to examine the way information is impounded in stock prices by providing an accurate reference point across time. In fact, this might be the most significant outcome of this study which could even be utilized by regulating authorities to scrutinize insider trading activity.

\subsection{Limitations of research}

Several limitations linger throughout this research. Perhaps the most important one is the subjective Evaluation of the Insider Trading Observation process. In fact, this process was meant to assist subjective evaluation of insider trading.

The Cumulated Abnormal Research benchmark was arbitrarily used. In all research, studied Abnormal Returns were cumulated based on data from reported, or identified after prosecution, Insider Trading. However, Reported Insider Trading is beyond the scope of this research.

The Event Detection process was constructed to a significant degree based upon personal judgment. As a result, it was finalized as soon as there was impression of a satisfactory level of accuracy. It has to be testified, though, that once the Event Detection process had been crystallized and values of the selected criteria had been set to those depicted in Fig. 2, results reported thereafter were generated only once. Additionally, according to the rather extensive Event Detection process validity assessment performed later, it was showed that the process was successful. The study focusing on events having a strongly positive impact on stock prices was performed. As a result, the arbitrarily selected $3 \%$ Real Return benchmark, set in Fig. 2, probably leads to the omission of Events for stocks with large capitalization.

Other limitations lie in the fact that, despite the overall parametrical approach followed throughout this research, certain procedures were implemented according to the selected dataset.

\subsection{Recommendations for future research}

The evaluation process of the Event Detection process was rather extensively presented to encourage cross examination, potentially on data from other stock markets. The Insider Trading Observation Environment could be further enhanced with other sources of information and more accurate news retrieval capabilities. The Event Detection process could be further widened by applying qualitative criteria like capitalization or sector characteristics. It would also be interesting to investigate whether 
there can be an automated procedure that would be able to suggest the optimum event detection parameters for each stock. Finally, the Event Study process could be enriched with a source of intraday transaction data which would be used to investigate more accurately insider trading activity.

\section{Competing interests}

The authors declare that they have no competing interests.

\section{Authors' contributions}

DM carried out the design of the study, supported the programming and performed the statistical analysis, AP had the full idea of this study, conducted the programming, the data selection and the testing part, while ET supported the whole process monitoring all the steps, discussed the statistical analysis, the outputs and the conclusions and demonstrated the study in conferences both in the US and in the Europe getting significant feedback and improved the study.

\section{References}

Commission Directive 2004/72/EC of 29 April 2004 implementing Directive 2003/6/EC of the European Parliament and of the Council as regards accepted market practices, the definition of inside information in relation to derivatives on commodities, the drawing up of lists of insiders, the notification of managers' transactions and the notification of suspicious transactions. Official Journal of the European Union L 162/70, 30.4.2004

Damodaran A, Liu CH (1993) Insider trading as a signal of private information. Rev Financ Stud 6(1):79119

Dasilas A (2007) Market reaction to dividend announcements: evidence from the Greek stock market, Working paper. Available at SSRN: http://ssrn.com/abstract=981885. Accessed 31 Oct 2008

Del Brio EB, Miguel A, Perote J (2002) An investigation of insider trading profits in the Spanish stock market. Q Rev Econ Finance 42:73-94

Directive 2003/6/EC of the European Parliament and of the Council of 28 January 2003 on insider dealing and market manipulation (market abuse). Official Journal of the European Union L 96/16, 12.4.2003

Fama EF (1970) Efficient capital markets: a review of theory and empirical work. J Finance 25(2):383-417. Papers and proceedings of the twenty-eighth annual meeting of the American Finance Association, New York, NY, December, 28-30, 1969 (May, 1970)

Fama EF (1991) Efficient capital markets: II. J Finance 46(5):1575-1617

Fama EF, Fisher F, Jensen MC, Roll R (1969) The adjustment of stock prices to new information. Int Econ Rev 10(1):1-21

Finnerty JE (1976a) Insiders and market efficiency. J Finance 31(4):1141-1148

Finnerty JE (1976b) Insiders' activity and inside information: a multivariate analysis. J Financ Quant Anal 11(2):205-215

Givoly D, Palmon D (1985) Insider trading and the exploitation of inside information: some empirical evidence. J Bus 58(1):69-87

Hillier D, Marshall AP (2002) Are trading bans effective? Exchange regulation and corporate insider transactions around earnings announcements. J Corp Finance 8:393-410

International Organization of Securities Commissions (2003) Insider trading: how jurisdictions regulate it. Report of the Emerging Markets Committee of the International Organization of Securities Commissions (IOSCO)

Jaffe JF (1974) Special information and insider trading. J Bus 47(3):410-428

Ke B, Huddart S, Petroni K (2003) What insiders know about future earnings and how they use it: evidence from insider trades. J Account Econ 35:315-346 
Keown AJ, Pinkerton JM (1981) Merger announcements and insider trading activity: an empirical investigation. J Finance 36(4):855-869

Kothari SP, Warner JB (2004) Econometrics of event studies. Working paper. Available at SSRN: http://papers.ssrn.com/sol3/papers.cfm?abstract_id=608601. Accessed 30 Oct 2008

LAW 3340/2005 For the protection of Capital market from actions of persons that possess inside information and market manipulation. Government Gazette A' 112/10-5-2005

MacKinlay AC (1997) Event studies in economics and finance. J Econ Lit 35(1):13-39

Meulbroek LK (1992) An empirical analysis of illegal insider trading. J Finance 47(5):1661-1699

Minenna M (2003) Insider trading, abnormal return and preferential information: supervising through a probabilistic model. J Bank Finance 27:59-86

Penman SH (1982) Insider trading and the dissemination of firms' forecast information. J Bus 55(4):479503

Seyhun HN (1992) The effectiveness of the insider-trading sanctions. J Law Econ 35(1):149-182

Seyhun HN, Bradley M (1997) Corporate bankruptcy and insider trading. J Bus 70(2):189-216 